\title{
SPLANCHNIC PRODUCTION AND UPTAKE OF ENDOGENOUS TRIGLYCERIDES IN THE FASTING STATE IN MAN *
}

\author{
By LARS A. CARLSON AND LARS-GÖRAN EKELUND \\ (From the Departments of Internal Medicine and Clinical Physiology, Karolinska Hospital, \\ and the King Gustaf $V$ Research Institute, Stockholm, Sweden)
}

(Submitted for publication November 26, 1962 ; accepted January 24, 1963)

An increased level of plasma triglycerides in the fasting state is one of the abnormalities of the plasma lipids encountered in patients with coronary heart disease $(1-4)$. There are probably several possible mechanisms that may give rise to increased fasting levels of plasma triglycerides, some of which might involve the liver, as this organ is the probable site of origin for at least part of the endogenous plasma triglycerides. It has been shown that the rat liver produces triglycerides in in vitro perfusion experiments $(5,6)$. In vivo it has been demonstrated that after injection of labeled acetate (7) or labeled FFA (8-10) to animals, radioactivity appears in the plasma triglycerides; this is practically abolished by hepatectomy. That the liver might have an important role in hyperlipemia in man was suggested by the observation that the turbid serum of a patient with essential hyperlipemia became clear during the course of a viral hepatitis (11).

The function of the endogenous plasma triglycerides is not fully elucidated. It is generally held that the fatty acids of the plasma glycerides represent a transport form of fatty acids from the liver to other sites, mainly adipose tissue. The available evidence for this view has been summarized (12). It must be emphasized, however, that this situation, with a net transport of fatty acids from the liver to adipose tissue, appears most likely to prevail during periods of positive caloric balance, as after a supply of calories to the liver, for example, in the form of carbohydrates or dietary fatty acids. In the postabsorbtive fasting state with negative caloric balance, however, there is no evidence of net transport of fatty acids to the adipose tissue from the liver. It is evident from published data (10) that after hepatectomy the concentration of plasma triglycerides in the dog

* This study was supported by a grant from the King Gustaf V 80th Birthday Foundation and grant H-7088 from the U. S. Public Health Service. does not decrease. This latter finding might be taken as a suggestion that neither adipose nor other tissues take up endogenous triglycerides in vivo during fasting conditions, if we assume that the major triglyceride production is abolished after hepatectomy.

From these points it seemed important to determine whether there is net production of triglycerides by the liver in the fasting state in vivo in man. Data from studies in man utilizing hepatic vein catheterization are presented in this paper. Net splanchnic production of triglycerides and of labeled plasma triglycerides after injection of labeled palmitate has been estimated.

\section{MATERIALS AND METHODS}

Three men, 40 to 50 years old, all subjectively in good health and physically fit, although two had previously had a myocardial infarction, were studied in the morning after fasting overnight. Except for the presence of coronary heart disease and elevated plasma lipids in two of the men, no other abnormalities were found in the clinical and laboratory examinations.

The hepatic vein was catheterized percutaneously from the femoral vein, and the position of the catheter checked by $\mathrm{X}$ ray and by the concentration of Bromsulphalein (sulfobromophthalein sodium) in the vein. When this catheter was in position, another catheter was inserted into the brachial artery and a third into a brachial vein. In the latter, a constant infusion of Bromsulphalein was given. Saline was infused slowly through the hepatic vein catheter. When all catheters were in place, the infusion of Bromsulphalein was started and was allowed to proceed for 45 minutes. Thereafter, samples for analysis were taken simultaneously from the artery and the hepatic vein by heparinized syringes. This was repeated twice at 10-minute intervals. Then an injection of albuminbound palmitate-1-C $\mathrm{C}^{14}$ was given. Simultaneous samples were drawn from the brachial artery and the hepatic vein for analysis at 10 -minute intervals. All three subjects felt quite comfortable during the entire study.

Estimation of hepatic blood floze. This was done in principle according to Bradley, Ingelfinger, Bradley, and Purry (13). When a priming dose of $150 \mathrm{mg}$ of Bromsulphalein had been given, a constant infusion of $6 \mathrm{mg}$ 
TABLE I

Arterial plasma lipid levels and plasma volume

\begin{tabular}{ccccc}
\hline $\begin{array}{c}\text { Case } \\
\text { no. }\end{array}$ & Cholesterol & $\begin{array}{c}\text { Phospho- } \\
\text { lipids }\end{array}$ & $\begin{array}{c}\text { Trigly- } \\
\text { cerides }\end{array}$ & $\begin{array}{c}\text { Plasma } \\
\text { volume }\end{array}$ \\
\hline & $m g / 100 m l$ & $m g / 100 m l$ & mmoles $/ L$ & $L$ \\
1 & 248 & 258 & 1.26 & 3.57 \\
2 & 330 & 343 & 2.70 & 3.22 \\
3 & 221 & 265 & 3.32 & 3.30 \\
\hline
\end{tabular}

per minute was started. The determinations of Bromsulphalein were done in duplicate with a standard error of about $1 \%$. The arterial concentration of Bromsulphalein remained constant after infusion for 45 minutes.

Estimation of blood iolume. The total blood volume was calculated from the values for total hemoglobin and hemoglobin concentration of finger blood, with the hemoglobin concentration assumed to be constant in the whole blood volume and the slight underestimation thus obtained disregarded. The standard error has been found to be about $5 \%$. The total amount of hemoglobin was determined with the alveolar cardiac output method of Sjöstrand (14) with the modification reported by Wiklander (15). The determination was done at least in duplicate.

Lipid analysis. Plasma triglycerides were determined in duplicate according to Carlson (16). Plasma FFA were analyzed according to Dole and Meinertz in duplicate (17).

Isotope determination. The plasma lipids were extracted in chloroform-methanol as described previously from this laboratory (18) in a slightly modified way. The extraction was completed within 5 minutes after the blood samples had been withdrawn. The lipid extract was separated on silicic acid into one fraction containing the cholesterol esters, one containing the triglycerides and the FFA, and one containing the phospholipids. The fraction containing the triglycerides and the FFA was separated on Amberlite IRA as described previously (18). After the addition of carrier fatty acid, the fractions containing the isolated triglycerides and the isolated FFA, respectively, were dried and dissolved in toluene containing $0.3 \%$ diphenyloxazole as scintillator and counted in an Ecco liquid scintillation counter. In model experiments the recoveries for these procedures are around $95 \%$. The entire procedure was carried out in duplicate, the standard error for the specific activity at reasonable activities being around $4 \%$.

Administration of palmitate-1-C $C^{14}$. Palmitic acid-1-C $C^{14}$ with a specific activity of around $20 \mathrm{mc}$ per mmoles was purchased from Amersham, England. The acid was neutralized and dissolved in $0.02 \mathrm{~N} \mathrm{NaOH}$, slightly warmed, and $6 \mathrm{ml}$ of human serum albumin ${ }^{1}$ as a $20 \%$ solution was added. The resulting solution was quite clear. A 5 -ml portion of this solution, containing around $10 \mu \mathrm{c}$, was injected intravenously.

${ }^{1}$ Kindly supplied by AB Kabi, Stockholm, Sweden.

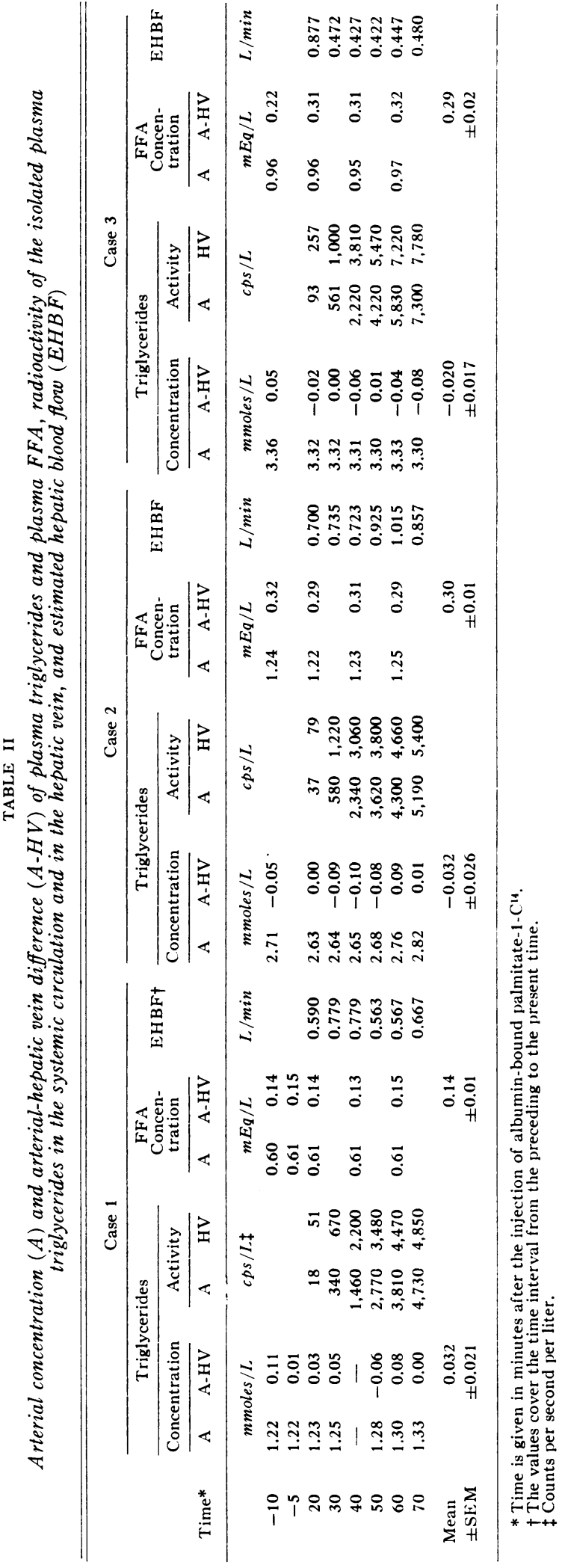


RESULTS

Plasma lipids during the experiment. The experimental results are given in Tables I and II. While Case 1 had normal fasting triglycerides, Cases 2 and 3 had moderately elevated levels of fasting triglycerides. The upper normal limit for this blood lipid fraction is around 2.2 mmoles per L (19).

The variation of the triglycerides and the plasma FFA during the procedure was small and well within the error of the methods (Table II). It is especially noteworthy that the FFA, which are known to respond rapidly to psychologic factors such as anxiety and discomfort (20), remained so constant during the study.

Arterial-hepatic vein difference of plasma lipids. The mean value for the arteriovenous difference over the splanchnic region of FFA and triglycerides is given in Table II, and a typical experiment is shown in Figures 1 and 2. The splanchnic region showed a significant uptake of FFA in all cases, as described previously in man by Gordon and Cherkes (21). On the other hand, no sta-

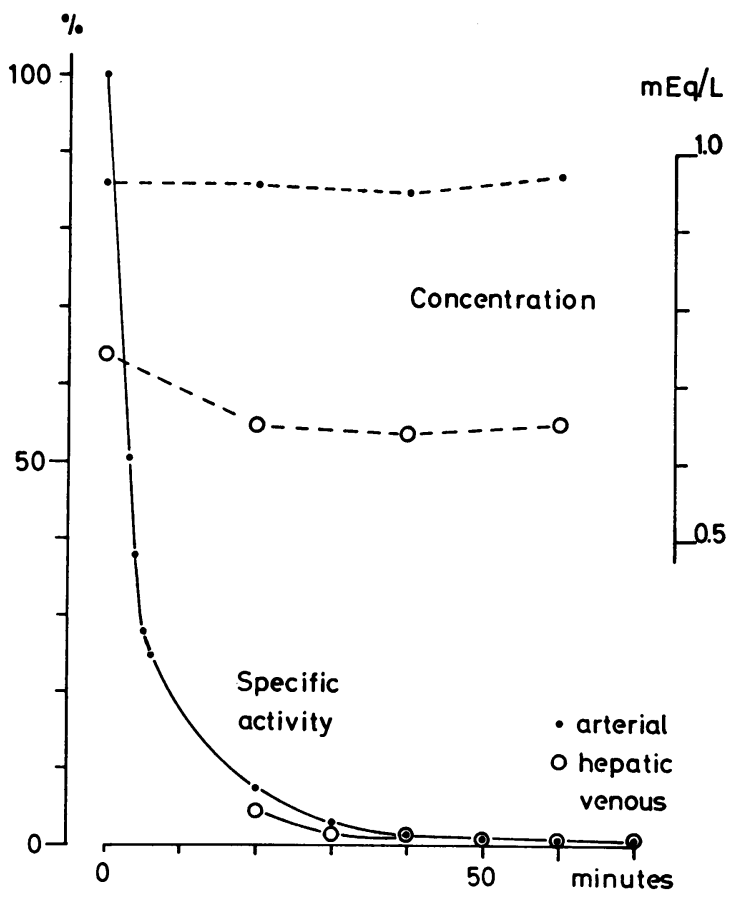

Fig. 1. Concentration (-- ) and specific activity (-) OF ARTERIAL AND hepatic venOUS FFA in CASE 3. Albumin-bound palmitate-1-C $\mathrm{C}^{\mathbf{1 4}}$ was injected at zero time. The calculated zero time specific activity is called $100 \%$.

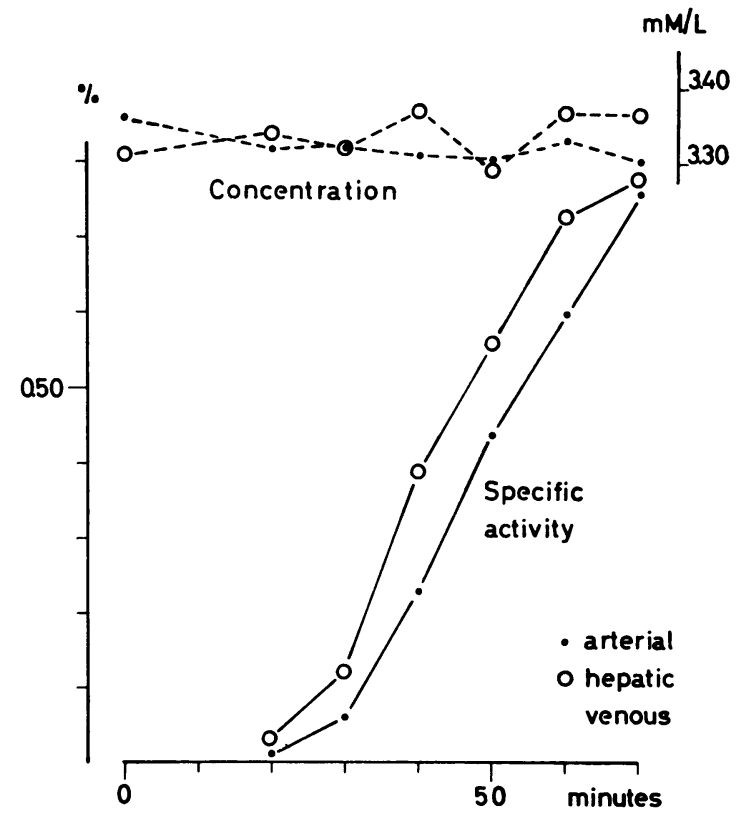

Fig. 2. Concentration (-- ) and SPECific activity (-) OF ARTERIAL AND hEPATIC VENOUS PLASMa TRIGLyCERIDES in CASE 3. The specific activity is expressed as percentage of the zero time specific activity of the plasma FFA.

tistically significant arteriovenous difference could be found for the plasma triglycerides.

Radioactivity in the plasma lipids. The results were qualitatively the same in all three cases. The data from Case 3 are given in Figures 1 and 2. The activity of the FFA declined after the injection with an initial half-life of 2 to 3 minutes. After 20 minutes significant radioactivity appeared in the triglycerides. After from 30 to 70 minutes this activity increased almost linearly in the arterial plasma as found previously after the injection of labeled palmitate in man (22). In all cases and samples the specific activity of the triglycerides was higher in the hepatic vein than in the arterial samples. This difference cannot be explained by the time of the blood's passage through the splanchnic region, as the possible error of the transit time at increasing arterial concentration would give the opposite result. ${ }^{2}$

\footnotetext{
2 Consider the possibility that the arterial concentration of a substance, $X$, is increasing with the time from some extra hepatic source. Then, samples drawn simultaneously from the artery and hepatic vein, at a time $t$, will give lower value in the vein, although $X$ is not extracted by the liver, because the venous sample corresponds to the arterial concentration at the time $t-\Delta t$, where $\Delta t$ is the time for passage of blood through the splanchnic region.
} 
TABLE III

Comparison between calculated total net splanchnic production of radioactivity in the triglycerides and total plasma radioactivity present in the isolated triglycerides at different time intervals after the injection of albumin-bound palmitate-1-C $C^{14}$ *

\begin{tabular}{|c|c|c|c|c|c|c|}
\hline \multirow[b]{2}{*}{ Time } & \multicolumn{2}{|c|}{ Case 1} & \multicolumn{2}{|c|}{ Case 2} & \multicolumn{2}{|c|}{ Case 3} \\
\hline & $\begin{array}{c}\text { Splanchnic } \\
\text { net } \\
\text { production }\end{array}$ & $\begin{array}{c}\text { Total } \\
\text { plasma } \\
\text { activity }\end{array}$ & $\begin{array}{l}\text { Splanchnic } \\
\text { net } \\
\text { production }\end{array}$ & $\begin{array}{c}\text { Total } \\
\text { plasma } \\
\text { activity }\end{array}$ & $\begin{array}{l}\text { Splanchnic } \\
\text { net } \\
\text { production }\end{array}$ & $\begin{array}{c}\text { Total } \\
\text { plasma } \\
\text { activity }\end{array}$ \\
\hline $\min$ & $c p s t$ & $c p s$ & $c p s$ & $c p s$ & $c p s$ & $c p s$ \\
\hline $20-30$ & 1,400 & 1,200 & 2,500 & 1,900 & 1,400 & 1,800 \\
\hline $20-40$ & 5,600 & 5,200 & 7,400 & 7,500 & 5,800 & 7,300 \\
\hline $20-50$ & 9,700 & 9,900 & 11,600 & 11,600 & 11,800 & 13,900 \\
\hline $20-60$ & 13,500 & 13,800 & 14,400 & 13,800 & 18,400 & 19,100 \\
\hline $20-70$ & 16,000 & 16,900 & 16,900 & 16,500 & 24,000 & 24,000 \\
\hline
\end{tabular}

* For detailed description, see text.

$\dagger$ Counts per second.

Calculation of mean net splanchnic production of radioactive triglycerides. The mean net splanchnic production of radioactivity in the plasma triglycerides $(Y)$ from time $t_{1}$ to $t_{2 .}$ was calculated as follows:

$$
Y=\frac{\left(A_{v_{1}}-A_{a_{1}}\right)+\left(A_{v_{2}}-A_{a_{2}}\right)}{2} \times F \times t \mathrm{cps},
$$

where $F=$ estimated splanchnic plasma flow (liters per minute), $A_{v}=$ activity in the isolated triglycerides in the hepatic vein (counts per second per liter), $A_{a}=$ activity in the isolated triglycerides in the arterial samples (counts per second per liter), $1,2=$ indexes referring to times $t_{1}$ and $t_{2}$, and $t=$ time from $t_{1}$ to $t_{2}$ (minutes).

This calculation was made for each 10-minute period from 20 minutes after the injection. The calculations are given in Table III. The net production is added for each time interval, i.e., the production at 70 minutes is the total calculated net production from the splanchnic region from 20 to 70 minutes after the injection of the labeled acid. This total net production of activity is compared in the same table with the activity present in the whole plasma space at the end of each period. These figures were obtained by multiplying the activity of the isolated triglycerides in arterial blood (counts per second per liter) by the plasma volume.

It is seen from the table that there is a good correspondence between the calculated total net production of activity and the activity present in the plasma compartment at all time intervals.

Calculation of splanchnic uptake of FFA and total flu. of $F F A$. The net splanchnic uptake of
FFA is calculated in Table IV, and amounted to about $22 \%$ of calculated total flux of FFA through plasma. The net splanchnic uptake thus calculated is mainly the result of uptake of FFA in the liver and in the rest of the splanchnic region as well as any release of FFA from omental adipose tissue. Furthermore, the titrated acidity comprises FFA to only $82 \%$ (17). Major changes, for example, in the concentration of cephalins over the liver, which contributes significantly to the titrated acidity, might thus influence the observed A-V difference.

\section{DISCUSSION}

Comparison of splanchnic production of inactive and radioactive triglycerides. In the fasting state no net production of triglycerides by the splanchnic region could be found. On the other hand, there was a significant production of radioactive tri-

TABLE IV

Splanchnic net uptake and calculated hepatic uptake of plasma FFA and total flux of FFA through plasma

\begin{tabular}{cccc}
\hline & $\begin{array}{c}\text { Cptake of } \\
\text { FF.t }\end{array}$ & \multicolumn{2}{c}{$\begin{array}{c}\text { Total flux of FFA } \\
\text { through plasma }\end{array}$} \\
\cline { 3 - 4 } $\begin{array}{c}\text { Case } \\
\text { no. }\end{array}$ & $\begin{array}{c}\text { Splanchnic } \\
\text { net uptake* }\end{array}$ & $\begin{array}{c}\text { Fractional } \\
\text { turnover } \\
\text { ratet }\end{array}$ & $\begin{array}{c}\text { Flux of } \\
\text { FFAf }\end{array}$ \\
\hline & $m E q /$ hour & min-1 $^{-1}$ & $m E q /$ hour \\
1 & 5.5 & lost & 67.0 \\
2 & 14.9 & 0.28 & 63.7 \\
3 & 9.1 & 0.23 & 43 \\
\hline
\end{tabular}

* Calculated from average splanchnic blood flow times average $\mathrm{A}-\mathrm{V}$ difference of FFA over the splanchnic region. + Estimated from the disappearance curve of the injected palmitate from 3 to 6 minutes after the injection.

$\ddagger$ Calculated as arterial concentration times plasma volume times fractional turnover. 
glycerides. It can be concluded from in vitro and in vivo experiments that these radioactive triglycerides must be derived mainly from active syntheses or transesterification in the liver $(5,6$, $8-10,22)$. The results indicate a rapid equilibration of the triglyceride fatty acids of the glyceride pools in the liver and in plasma without significant net production of triglycerides. In vitro studies with rat liver slices have, in conformity with these data, shown not only a secretion of radioactive triglycerides to the medium, but also an uptake of triglycerides from the medium (23). In the rat, it has also been shown by Laurell that injected labeled plasma triglycerides indeed have a rapid turnover with an initial half-life time of about 3 to 5 minutes (24). This rapid initial turnover might well be due to the splanchnicplasma exchange of triglycerides.

Transport of triglycerides to the periphery. Since the plasma triglyceride concentration remained constant during the study, it should be possible to estimate the transport of triglycerides from the splanchnic region to the periphery from the data on the splanchnic production of inactive as well as of radioactive triglycerides.

No significant production of chemically determined triglycerides was found, which in the steady state indicates that no net transport to the periphery occurred.

There are, however, two limitations in the methods used which must be emphasized. First, the methodological error in the determination of the triglycerides was, in the cases studied, within \pm 0.02 mmoles per $L$. This means that the net production could not have been more than $0.7 \times$ $0.05 \times 60=2$ mmoles per hour (mean splanchnic plasma flow $=0.7 \mathrm{~L}$ per minute), but it could have been less. Secondly, we have only determined the glycerol part of the triglycerides and the possibility of a difference in concentration of diand monoglycerides over the splanchnic area might exist. If there were a high concentration of partial glycerides in the systemic blood and a low one in the hepatic venous blood, a net production of fatty acids in the glycerides would exist. However, the concentration of di- and monoglycerides is low in peripheral blood (25).

Furthermore, the calculated net splanchnic production of radioactive triglycerides up to $70 \mathrm{~min}$ - utes agreed well with the estimated amount of radioactivity circulating in the plasma compartment at that time. This indicates that the transport to the periphery of radioactive triglycerides during the time studied is smaller than the errors of the methods used for the estimation. If we assume a random error for the procedures used to be about $5 \%$, a difference of about 2,400 cps (counts per second) between net production and recovered amount would be within the limit of the methods in Case 3. Since the mean specific activity in the plasma triglycerides was about 1,000 cps per mmole from 20 to 70 minutes, we once again reach a figure of around 2 mmoles per hour for the maximal possible net transport of triglycerides to the periphery.

There are also some systematic errors involved in the methods used. The estimated splanchnic blood flow is subject to small positive errors. The use of $\mathrm{A}-\mathrm{V}$ difference at increasing concentration tends to make the observed difference too low due to the transit time. Both these errors might cause the calculated net production to be too low. However, the amount calculated to be present in the plasma compartment might also be too low due to the slight underestimation of the blood volume.

General discussion. In the fasting state lipogenesis is low and thus not a major precursor of the triglyceride fatty acids in the liver (26). The major source would then be FFA. The hepatic uptake of FFA is not known in the subjects studied. Studies in rats $(27,28)$ and in rabbits (29) indicate that about $30 \%$ of the FFA flux is taken up by the liver. Our figure for estimated net splanchnic FFA uptake was $22 \%$ of the plasma flux. If FFA is the major oxidized substrate in the fasting liver, then about $10 \mathrm{mEq}$ of FFA would be oxidized per hour, as the oxygen consumption of the liver is $5 \mathrm{~L}$ per hour (30). As a matter of fact, the mean calculated uptake of FFA in the splanchnic region was $10 \mathrm{mEq}$ per hour in the cases studied. If we assume that the splanchnic uptake underestimates hepatic uptake of FFA within $30 \%$, due to FFA release from omental fat, as judged from the animal data, there would be at the most $5 \mathrm{mEq}$ of FFA taken up by the liver per hour, which might be used for net transport to the periphery. This figure is very close to the estimated possible maximal peripheral 
triglyceride fatty acid transport of $6 \mathrm{mEq}$ per hour. However, FFA taken up by the liver in amounts exceeding the oxidative needs have other possible pathways, such as storage in the liver and conversion to ketone bodies.

It is recognized that the technique with observation of arterial-hepatic vein difference includes studies not only over the liver but also over the adipose tissue located in the splanchnic region and the intestines. The possible contribution of tissues other than the liver to our data can be studied directly only by means of portal vein blood samples.

\section{SUMMARY}

The net splanchnic production of triglycerides and of radioactive triglycerides after the injection of albumin-bound palmitate-1-C $\mathrm{C}^{14}$ was studied simultaneously in the fasting state in man by liver vein catheterization.

No net production of triglycerides could be demonstrated over the splanchnic region.

$\mathrm{Up}_{\mathrm{p}}$ to 70 minutes after the injection of labeled palmitic acid there was a significant splanchnic net production of radioactive triglycerides. The estimated splanchnic net production of radioactive triglycerides compared well with the calculated amount of radioactive triglycerides present in the plasma compartment.

The data have been taken as an indication that. considering methodological errors, the net transport of triglycerides to the periphery was less than \pm 2 mmoles per hour. Furthermore, the data indicate that there is a rapid exchange of triglyceride fatty acids between the liver and plasma triglyceride pools. This process was much more rapid than any net transfer of triglycerides from these pools to the periphery.

\section{REFERENCES}

1. Albrink, M. J., and E. B. Man. Serum triglycerides in coronary artery disease. Arch. intern. Med. 1959, 103, 4.

2. Antonis, A., and I. Bersohn. Serum triglyceride levels in South African Europeans and Bantu and in ischæmic heart-disease. Lancet 1960, 1, 998.

3. Carlson, L. A. Serum lipids in men with myocardial infarction. Acta med. scand. 1960, 167, 399.

4. Havel, R. J., and L. A. Carlson. Serum lipoproteins, cholesterol and triglycerides in coronary heart disease. Metabolism 1962, 11, 195.
5. Stein, Y., and B. Shapiro. Assimilation and dissimilation of fatty acids by the rat liver. Amer. J. Physiol. 1959, 196, 1238.

6. Kay, R. E., and C. Enteman. The synthesis of "chylomicron-like" bodies and maintenance of normal blood sugar levels by the isolated, perfused rat liver. J. biol. Chem. 1961, 236, 1006.

7. Harper, P. V., W. B. Neal, Jr., and G. R. Hlavacek. Lipid synthesis and transport in the dog. Metabolism 1953, 2, 69.

8. Laurell, S. Distribution of $\mathrm{C}^{14}$ in rats after intravenous injection of non-esterified palmitic acid-1- $\mathrm{C}^{\mathbf{1 4}}$. Acta physiol. scand. 1959, 46, 97.

9. Borgström, B., and T. Olivecrona. The metabolism of palmitic acid-1- $\mathrm{C}^{14}$ in functionally hepatectomized rats. J. Lipid Res. 1961, 2, 263.

10. Havel, R. J., and A. Goldfien. The role of the liver and of extrahepatic tissues in the transport and metabolism of fatty acids and triglycerides in the dog. J. Lipid Res. 1961, 2, 389.

11. Carlson, L. A., and B. Olhagen. Studies on a case of essential hyperlipemia. Blood lipids, with special reference to the composition and metabolism of the serum glycerides before, during and after the course of a viral hepatitis. J. clin. Invest. 1959, 38, 854.

12. Olson, R. E., and J. W. Vester. Nutrition-endocrine interrelationships in the control of fat transport in man. Physiol. Rev. 1960, 40, 677.

13. Bradley, S. E., F. J. Ingelfinger, G. P. Bradley, and J. J. Curry. The estimation of heaptic blood flow in man. J. clin. Invest. $1945,24,890$.

14. Sjöstrand, T. A method for the determination of the total hemoglobin content of the body. Acta physiol. scand. 1948, 16, 211.

15. Wiklander, O. Blood volume determinations in surgical practice. Acta chir. scand. 1956, suppl. 208.

16. Carlson, L. A. Determination of serum glycerides. Acta Soc. Med. upsalien. 1959, 64, 208.

17. Dole, V. P., and H. Meinertz. Microdetermination of long-chain fatty acids in plasma and tissues. J. biol. Chem. 1960, 235, 2595.

18. Carlson, L. A., and L. B. Wadström. A colorimetric method of determining unesterified fatty acids in plasma. Scand. J. clin. Lab. Invest. 1958, 10, 407.

19. Carlson, L. A. Serum lipids in normal men. Acta med. scand. 1960, 167, 377.

20. Havel, R. J., and A. Goldfien. The role of the sympathetic nervous system in the metabolism of free fatty acids. J. Lipid Res. 1959, 1, 102.

21. Gordon, R. S., Jr., and A. Cherkes. Unesterified fatty acid in human blood plasma. J. clin. Invest. 1956, 35, 206.

22. Carlson, L. A. Studies on the incorporation of injected palmitic acid-1-C $\mathrm{C}^{\mathbf{1 4}}$ into liver and plasma lipids in man. Acta Soc. Med. upsalien. 1960, 65,85 . 
23. Hamosh, M., and B. Shapiro. Lipid release by liver slices. Amer. J. Physiol. 1961, 201, 1030.

24. Laurell, S. Recycling of intravenously injected palmitic acid-1-C $\mathrm{C}^{\mathbf{1 4}}$ as esterified fatty acid in the plasma of rats and turnover rate of plasma triglycerides. Acta physiol. scand. 1959, 47, 218.

25. Carlson, L. A., and L. B. Wadström. On the occurrence of tri-, di- and monoglycerides in human serum. Third International Conf. Biochem. Problems in Lipids, Brussels, 1956, p. 123.

26. Lyon, I., M. S. Masri, and I. L. Chaikoff. Fasting and hepatic lipogenesis from $\mathrm{C}^{\mathbf{1 4}}$-acetate. J. biol. Chem. 1952, 196, 25.
27. Bragdon, J. H., and R. S. Gordon, Jr. The distribution of $\mathrm{C}^{14}$ after the intravenous injection of labeled chylomicrons and unesterified fatty acids in the rat. J. clin. Invest. 1958, 37, 574.

28. Olivecrona, $T$. The metabolism of 1-C $C^{14}$-palmitic acid in the rat. Acta physiol. scand. 1961, 59, 295.

29. Havel, R. J., J. M. Felts, and C. M. Van Duyne. Formation and fate of endogenous triglycerides in blood plasma of rabbits. J. Lipid Res. 1962, 3, 297.

30. Fritz, I. B. Factors influencing the rate of longchain fatty acid oxidation and synthesis in mammalian systems. Physiol. Rev. 1961, 41, 52. 